\title{
La postura crítica y la pesquisa en el
}

Diseño Gráfico

Por: Luis Henry Vanegas 0.

Docente Diseño Gráfico

Areandina, sede Bogotá.

\section{Algo de contexto}

El diseño es considerado desde el principio de los siglos como algo necesario en la vida humana, en tanto reúne las vertientes que abrevan en la necesidad y la solución, elementos atinentes al ser desde sus inicios. En medio del potencial abanico de aspectos, se sitúa la gráfica como fenómeno que convive con cada uno de nosotros, necesitados de expresar con otros lenguajes las percepciones acerca de la realidad particular.

Sin embargo, ese lenguaje ha superado la expectativa de ser una forma de mostrar las realidades y subjetividades, tendiendo a convertirse en una mediación que la sociedad de consumo ha adoptado utilitariamente, al ofrecer sus productos y servicios. 
Ascendido a profesión en tanto sus cultores profesionales han estudiado su implicación en la comunicación humana, la faceta del mero consumismo fue superada, siendo hoy expresado gráficamente y visto (usado) como dispositivo comunicacional que nos permite, apoyados en las formas y figuras, hacer sentir la realidad subjetiva en el otro, valiéndose de la conmoción perceptiva que provoca la imagen cuando toca la sensibilidad estética del ser. Podría considerarse la alteridad como unos de sus principios; agregando la funcionalidad y la técnica. Esa metamorfosis ha desplegado tensiones y fisuras que hacen necesaria la revisión del quehacer y de los componentes de la profesión; por supuesto, la intención del presente escrito no es agotar la temática, es analizar algunos de estos queriendo heredarle, en tono reflexivo, elementos que sirvan (al menos en nuestro medio) para dar apertura al estudio sensato que legitime la profesión.

Una aproximación prudente a la temática nos permitirá ver la evolución de lo que en sus comienzos fue entendido más como un oficio, pero que paulatinamente ha ido posicionándose y tomando forma de actividad profesional, al punto de ser hoy parte atractiva de la oferta de programas de formación que conforman el portafolio de universidades e instituciones de educación superior, bajo distintas denominaciones correspondientes y a su vez a diversos campos de acción y finalidades laborales. 


\section{La resultante 3 por 1}

Sin embargo, esa misma diversidad ha provocado ausencia de distinción entre los mencionados campos de acción, al punto de encontrarse revueltos sus objetos, no disfrutando de "suficiente claridad" sobre cuáles son sus verdades conceptuales, su distinción formativa, sus características, ni sus objetivos.

\section{Ley 30 de diciembre 28 de 1992}

Artículo $7^{\circ}$ Los campos de acción de la Educación Superior, son: el de la técnica, el de la ciencia, el de la tecnología, el de las humanidades, el del arte y el de la filosofía. (Educación, 1992)

La coyuntura ha sido aprovechada de manera perjudicial por intereses mezquinos, favorecidos por tal condición cultural incubada progresivamente de forma por demás difusa, de suerte que el "caos" provocado con la interpretación de las especificidades, poco ha colaborado cuando se desea establecer el horizonte formativo de las mismas (todas útiles) a efecto de proyectar la distinción de los correspondientes perfiles curriculares, profesionales, ocupacionales, para determinar las potencialidades (competencias) de los egresados de una y otra línea formativa.

A tiempo que todo esto surge, permite la entrada de un sinnúmero de conjeturas emitidas por tal o cual, a veces $\sin$ la menor dosis de sentido y tanto menos crítico, en torno a las diversas resultantes (procesos y productos) que emite cada ruta formativa. He aquí un interrogante problémico de carácter crítico: ¿Hasta dónde llega el efecto o la misionalidad de cada uno? Esa problemática ha generado, como se ha dicho, tensiones al interior de las instituciones y de la profesión misma.

Queriendo proponer una luz que permita discernir el quehacer, me permitiré invocar un concepto de Massimo Vignelli (1983), tratadista del tema académico acerca de las necesidades del diseño gráfico; asombra la indiferencia académica hasta nuestros días, ya que la citada proclama fue generada hace ya algunos años durante el discurso inaugural del Symposium sobre la Historia del Diseño Gráfico - University Chicago 


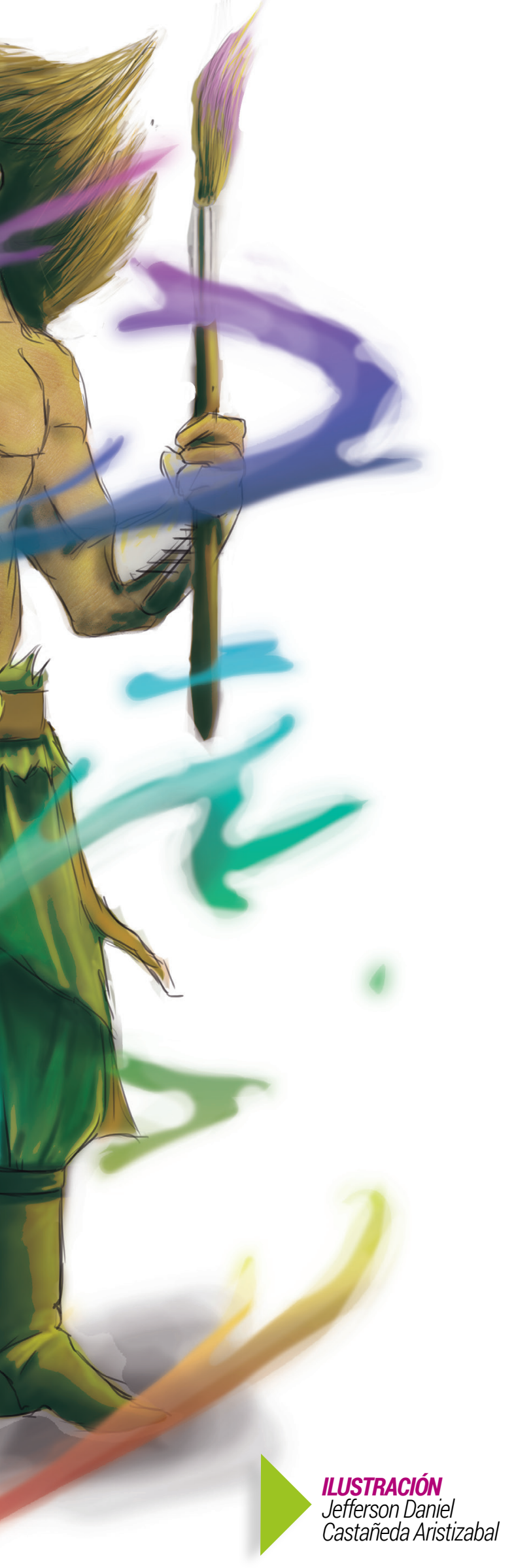

Press, considerado por el ponente como una "oportunidad histórica" (Vignelli, 1983). Primero acerca del quehacer y pertinencia de la profesión y por ende, el mencionado factor contribuyendo a la no presencia de su correspondiente destino formativo.

Desde su óptica, el autor configura coloquialmente "una lista de compra", en el sentido de aportar miradas acerca del devenir profesional, irónicamente "diseñando" las necesidades que la aquejan. Entresaco dos tópicos de carácter neurálgico que someramente van a servir de excusa para este abordaje: la Criticidad y la Investigación. Me permitiré articular los dos alternamente vinculados, considerando que dependen biunívocamente y en esa medida se corresponden.

\section{El diseño es causalidad no casualidad}

Es la razón de ser de su acción y aspecto crítico que convoca la indagación que debe anteceder a la ejecutoria, para obrar con precisión. No se concibe una solución de diseño a medias, su efecto debe ser, en la medida de la demanda, una respuesta concreta y evaluable; luego, para garantizar su congruencia con el objetivo que proponga, debe consultar con rigor la necesidad y el proceso para escoger las herramientas, las tecnologías y los conceptos que propicien un resultado legítimo, aspecto que el pensador propone grosso modo, como categórico en el recorrido y que, en mi concepto, el diseño ha emprendido (sobre todo en nuestro medio) casi a ciegas por falta de sentido de compromiso y pertenencia por la profesión.

A tiempo que escribo estas líneas asumo la responsabilidad autocritica, entendiendo que momentos como el presente han hecho falta en la academia y que en general han escaseado en la vida del diseño, por considerar entre otras hipótesis, que el diseño es una actividad nueva, joven, y que como tal, hay tiempo para ocuparnos de su estudio, este miramiento le causa complicaciones. Cabría entonces la pregunta ¿A partir de cuándo no lo será? 
Ahora bien, ¿Requiere del componente investigativo para actuar?, ¿Qué actividad profesionista no lo demanda?, ¿Cuándo se sabe que su recreación teórica depende de los caminos que le vaya revelando la indagación, observando, describiendo, explicando?, en fin, manteniendo actual su vigencia reconfigurando su paradigma, discursividad que brilla por su ausencia para que se presente el diseño primero como profesión legítima y como tal soportada por un presupuesto teórico.

"En la versión platónica, un paradigma constituye no un simple modelo, a modo de "copia", "patrón" o "muestra" de algo que es real, sino, mucho más que eso: un paradigma es un modelo ejemplar, es decir, perfecto de tal modo que se ha de considerar digno de ser seguido e imitado" (González, 2005)

¿Qué cosas de las que vemos, parecen poseer la completud de elementos ineludibles para ser una obra y que con ellos se correspondan las exigencias para las que fueron concebidas y creadas? por añadidura, ¿cuáles en su defecto no? Como podemos ver, tanto la indagación como el sentido crítico potencian las respuestas e infieren certezas para que luego ni el sujeto gestor ni el sujeto usuario, recurran a elementos antojadizos en el proceso de generar y causar bienestar al ser (Principio Ontológico del proceso de diseño). La iluminación que manifiesta la consideración resultará aún más fortalecida comprendiendo el diseño como actividad embebida en sangre comunicacional, con lo cual se alimentarán continuamente el qué y el para qué del proceso.

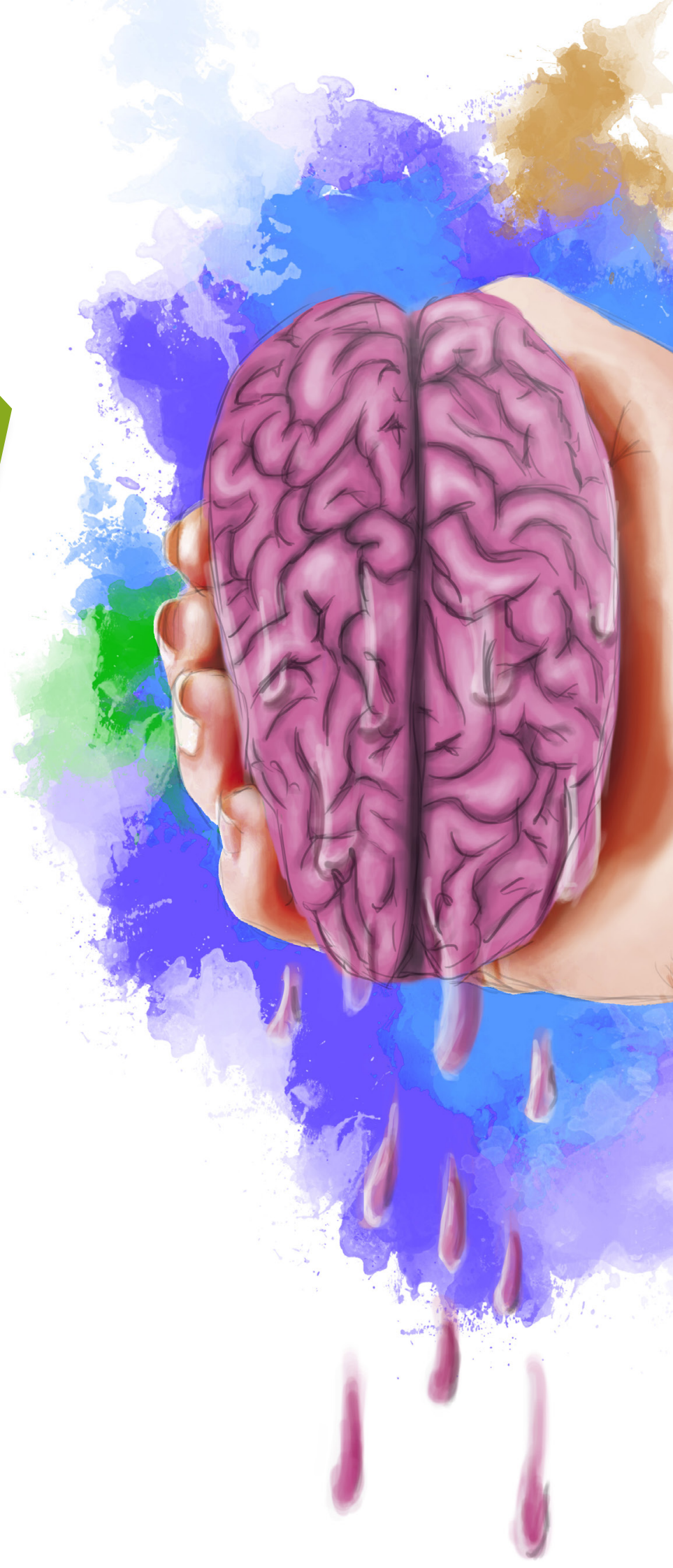


ILUSTRACIÓN

Jefferson Daniel

Castañeda Aristizabal

Se evidencia que en la conceptualización perviven elementos culturales que impiden fomentar con mayor asiduidad y precisión; algunos componentes que co-laboren con actitud crítica pero estimulante de su crecimiento, frente a lo visual-función. Esto, pues la experiencia indica que toda persona que ve se siente con suficiente autoridad para opinar sobre el hecho gráfico visto. Pero ¿Qué provoca esta "participadera"?

El diseño padece de una enfermedad cuyo fondo es el desconocimiento social en torno a su importancia como disciplina (y profesión) que desempeña un importante papel social en el desarrollo del individuo, de su entorno social y económico - productivo. Una sociedad sin productos gráficos estaría condenada a morir de inanición informativa; todo producto gráfico nutre particularmente las actividades profesionales y la cotidianidad del res cogitans. Aun así, no se aprecia como prioritaria su pertinencia.

A diario damos cuenta de la aparición de una gran diversidad de productos visuales emergidos en medio de la comunicación gráfica, más no siempre emitidos por alguien probo en la temática; por el contrario, casi siempre ajeno y guiado por la subjetividad, sin explorar componentes distintos a esa categoría creativa. Afloran en ese tránsito por parte del sujeto usuario, expresiones coloquiales tales como: ..."Yo creería que"..., "A mí no me parece; pero bueno...", "Hay algo que a mí no me gusta"... etc. Toda suerte de conjeturas brotan cuando se pone en consideración ya de un cliente, ya de un par colega (incluso), ya de un sapiente, pero aun así, las argumentaciones aparecen ausentes de teoría, demasiado subjetivizadas, no apegadas al menos a ciencias auxiliares en las que el diseño pueda beber en arriendo, como es la sicología cuando se hable de percepción subjetiva, dado que "Todo mundo ve de lo que sabe". La experiencia indica que toda persona que ve, se siente con suficiente autoridad (criterio) para opinar sobre el hecho gráfico visto.

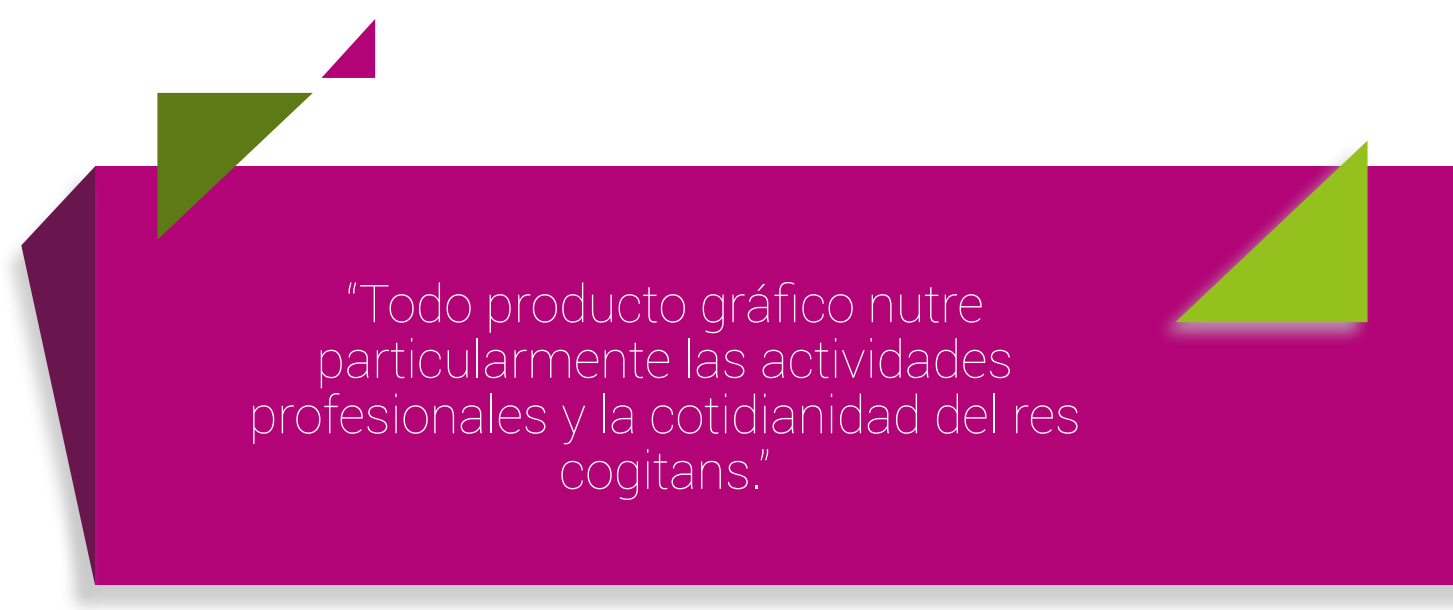


"Captamos la información visual de muchas maneras. Las fuerzas, perceptivas y kinestésicas, de naturaleza fisiológica, son vitales para el proceso visual (...) El cómo vemos el mundo afecta casi siempre a lo que vemos. Después de todo, el proceso es muy individual en cada uno de nosotros. El control de la mente viene frecuentemente programado por las costumbres sociales." (Dondis, 1967)

\section{COMOVEMOS EL MUNDO}

Otra resultante de tal "participadera". El sentido crítico y el componente indagador, aún son incipientes. Por tal razón, el criterio pedagógico de los principios y fundamentos le compete al diseño en términos de socializar las bondades mediadoras de lo visual. Se puede pensar que combinados dotarían elementos que permitan evidenciar fortalezas que, a su vez, posibiliten la distinción mediante la reflexión sobre los insumos que broten de tal actividad y potencien el sentido tanto de la formación como de los productos concebidos desde cada quehacer. técnico, tecnológico y profesional, junto a la identidad de sus papeles y la coherencia con sus funciones. Las distinciones surgidas privilegiarían el sentido comunicacional del componente respectivo, colaborando en la configuración y consolidación de sus objetos de estudio, de por sí alimentadores de lo teorético del diseño.

En tal propósito, la creación de sentido acerca de las fortalezas de su atributo cultural como creador de interacciones, conspira para que exista una sólida educación social, diseminada en la concienciación en torno al potencial de la figura y su imagen e imaginarios; de la trascendencia de las narrativas particulares del hecho gráfico, la categorización de las interpretaciones que fluyen, la emergencia de los efectos en términos de evaluación de efectividad; entre muchos componentes atribuibles al espacio profesional finamente encargado al profesional del diseño gráfico. 
A manera de conclusión, algunos componentes que se oponen al éxito solicitado al Diseño Gráfico, con la finalidad de ir diseñando un Norte que proponga y configure el criticismo visual y la potenciación del sentido indagador, como insumos imprescindibles para su establecimiento como actividad importante en los renglones económico, estético, social entre otros:

- La producción critica. Factor sustancial en la creación de sentido de actividad y de las realizaciones mismas.

-La asunción del componente critico como útil en la construcción de su discurso teórico profesional.

-Apropiación del trabajo de indagación requerido, para optar la solución pertinente al caso gráfico y blindar los resultados.

- La escasa distinción entre sus diferentes modalidades formativas (campos).

- La vigilancia oficial sobre el sentido de las denominaciones con que se estos se ofrecen.

- La indiferencia social frente a esta gama de dificultades y la apatía académica de sus cultores.

-El divorcio provocado por la NO inclusión del Diseño Gráfico como faceta visual de la cultura Comunicacional.

\section{$\overline{\text { Lista de Referencias }}$}

Dondis, D. (1967). Sintaxis de la Imagen. Sintaxis de la Imagen, alfabetidad visual. Editorila Gustavo Gilli.

Educación, M. d. (28 de Diciembre de 1992). Ley 30 de la Educación Superior. Bogotá, Colombia.

Gonzalez, F. (1 de Abril de 2005). ¿Qué es un paradigma? Análisis teórico, conceptual y psicolingüístico del término. Investigación y Postgrado. Caracas, Venezuela: Universidad Pedagógica Experimental Libertador.

Vignelli, M. (1983). DISCURSO INAUGURAL DEL SYMPOSIUM SOBRE LA HISTORIA DEL DISEÑO GRÁFICO. Chicago : Chicago Press. 